\title{
Comparing the Impact of Environmental Factors During Very High Gravity Brewing Fermentations
}

\author{
Luis Lima ${ }^{1, *}$, Tiago Brandão ${ }^{2}$, Nelson Lima ${ }^{1}$ and José António Teixeira ${ }^{1}$
}

\begin{abstract}
J. Inst. Brew. 117(3), 359-367, 2011

The impact of the initial dissolved oxygen, fermentation temperature, wort concentration and yeast pitching rate on the major fermentation process responses were evaluated by full factorial design and statistical analysis by JMP 5.01 (SAS software) software. Fermentation trials were carried out in 2L-EBC tall tubes using an industrial lager brewing yeast strain. The yeast viability, ethanol production, apparent extract and real degree of fermentation were monitored. The results obtained demonstrate that very high gravity worts at $22^{\circ} \mathrm{P}$ can be fermented in the same period of time as a $15^{\circ} \mathrm{P}$ wort, by raising the temperature to $18^{\circ} \mathrm{C}$, the oxygen level to about $22 \mathrm{ppm}$, and increasing the pitching rate to $22 \times 10^{6}$ cell $/ \mathrm{mL}$. When diluting to obtain an $11.5^{\circ} \mathrm{P}$ beer extract, the volumetric brewing capacity increased $91 \%$ for the $22^{\circ} \mathrm{P}$ wort fermentation and $30 \%$ using the $15^{\circ} \mathrm{P}$ wort. After dilution, the fermentation of the $22^{\circ} \mathrm{P}$ wort resulted in a beer with higher esters levels, primarily the compound ethyl acetate.
\end{abstract}

Key words: brewing, high-gravity worts, oxygen, pitching-rate, temperature.

\section{INTRODUCTION}

Fermentation is the most time-consuming step of a lager brewing process, and plays a key role in the industrial performance of a brewery. To make brewing fermentations more profitable, several approaches have been presented, such as continuous fermentation with immobilized yeast in high cell density bioreactors ${ }^{3}$ and optimization of the fermentation variables. Fermentations can be optimized by improving the brewer's yeast phenotype ${ }^{5,21,26}$, or adjusting the environmental conditions of the process $^{6,27,37,46}$, leading to faster fermentations keeping the brewery quality standards.

Increasing the wort concentration can be a viable option to improve the volumetric yield in the process of industrial brewing, with a reduction of energy, water,

\footnotetext{
${ }^{1} \mathrm{IBB}$ - Institute for Biotechnology and Bioengineering, Centre of Biological Engineering, Campos de Gualtar, 4710-057 Braga, Portugal.

${ }^{2}$ Unicer - Bebidas de Portugal, SGPS, SA; P.O. Box 1044, 4466955 S. Mamede Infesta, Portugal.

*Corresponding author. E-mail: luislima@deb.uminho.pt
}

Publication no. G-2011-1018-1155

(c) 2011 The Institute of Brewing \& Distilling labour, cleaning and effluent costs. The brewery can also become more flexible producing different types of beers from the same high concentrated batch. In general, brewing $12^{\circ} \mathrm{P}$ wort produces beer with $5 \%(\mathrm{v} / \mathrm{v})$ ethanol, while higher ethanol concentrations are obtained by high gravity (HG) brewing, $16^{\circ} \mathrm{P}-18^{\circ} \mathrm{P}$. This procedure needs a downstream dilution step with oxygen free water to regulate the extract/ethanol content of the final beer.

However, there are several aspects that have to be considered when the wort extract is raised to certain values. Depending on the limit of the brewing process, there is the potential risk of having large amounts of extract that will not be converted during fermentation and losing extract as a consequence of the altered yeast performance. The osmotic stress caused by the high solute concentrations, and the consequent increase in ethanol accumulation during the fermentation, have a direct impact on yeast performance $e^{7-10,14,23,32,33,40,41,43,50}$. The combination of these factors can result in a distinct aromatic profile beer with higher levels of acetate ester in comparison to a beer produced using a low extract wort ${ }^{46}$.

Many approaches have been presented to overcome HG and very high gravity (VHG) fermentation drawbacks. The physiological condition of the yeast cells, the pitching rate and the fermentation conditions must be highlighted when the wort concentration is raised ${ }^{22,37-}$ 39,56,58. The adjustment of dissolved oxygen concentration plays an important role in yeast physiology and the consequent robustness of the yeast ${ }^{11,13,38}$. This is important for the success of VHG fermentations. Fermentation temperature has been considered to accelerate HG and VHG fermentations. It has a direct effect on the fermentation rate through its effect on yeast growth and metabolism. Although most brewing yeast strains have a maximum growth temperature, within the range of $30^{\circ} \mathrm{C}-35^{\circ} \mathrm{C}$, there are flavour active compounds and ethanol losses by gas stripping due the vigour of the fermentations at the higher temperature ranges. Higher pitching rates can also accelerate sugar uptake and ethanol production in $\mathrm{HG}$ and VHG worts, shortening the fermentation time; however, higher diacetyl level in the green beer can occur ${ }^{20,51,55}$. Changes in the yield factors are expected to occur as brewing fermentations are dependent on process variables, as well as the formation of aroma active compounds, such as higher alcohols ${ }^{4,7,17,25,30,45,46,49}$ esters $^{2,42,47,57}$ and acetaldehyde ${ }^{29}$. The presence of higher alcohols and esters is strongly dependent on the wort composition and extract $^{17,49}$, fermentation temperature ${ }^{25,46}$, wort oxygen 
content $^{4,45}$, yeast growth, carbon dioxide pressure ${ }^{45}$, yeast pitching rate, and yeast strain.

The optimization of brewing fermentations has been studied using modelling tools in order to understand variations in the beer profile caused by the process variables $^{12,18,44,53,54}$. In this study, the focus was on the evaluation of the effect of environmental factors such as wort concentration, dissolved oxygen, temperature and yeast pitching rate on the productivity parameters of a brewing fermentation, with an industrial lager brewer's yeast strain, with the application of a full factorial design. The final goal was to optimize the fermentation process considering the end point of the primary fermentation.

\section{MATERIALS AND METHODS}

\section{Yeast strain and propagation}

A lager brewing yeast strain of Saccharomyces cerevisiae var. uvarum (Unicer Strain II) was utilized. Yeast was propagated from $-80^{\circ} \mathrm{C}$ glycerol stock aliquots in $15^{\circ} \mathrm{P}$ wort at $27^{\circ} \mathrm{C}$ in Erlenmeyer flasks to obtain yeast biomass to pitch 2 litres of wort. The propagated yeast was recovered by filtration with a $0.44 \mu \mathrm{m}$ sterilized filter. Compressed yeast mass was quantified according to mass and cell counting correlation by suspending a weighted portion of the yeast, followed by a microscopic counting, using an Improved Neubauer counting camera.

\section{Wort and fermentation conditions}

Lager wort, $15^{\circ} \mathrm{P}$ and $22^{\circ} \mathrm{P}$, was brewed according to standard production procedures and the composition is presented in the Table I. All worts were produced using malt and corn grits, maintaining the same ratio. The $\mathrm{pH}$ of all worts was $5.1 \pm 0.1$. Brewing fermentations were performed in $2 \mathrm{~L} \mathrm{EBC}$ tall tubes fermenters at a controlled temperature $^{1}$. During oxygenation or aeration, the wort temperature was maintained at $8^{\circ} \mathrm{C}$, until the wort pitching step. Pressurized air was used to reach an oxygen level of $10 \mathrm{ppm}$; to achieve levels over $20 \mathrm{ppm}$, pure oxygen gas was used. The wort oxygen content was measured by a $\mathrm{CO}_{2} / \mathrm{O}_{2}$ Gehaltemeter (Norit Haffman, Borne) and

Table I. Wort composition of the standard and the very high gravity worts.

\begin{tabular}{|c|c|c|}
\hline & VHG wort & Standard wort \\
\hline Wort concentration $\left({ }^{\circ} \mathrm{P}\right)$ & 22.06 & 14.82 \\
\hline Apparent extract $(\% \mathrm{~m} / \mathrm{m})$ & 22.21 & 14.29 \\
\hline Density & 1.09276 & 1.05800 \\
\hline Colour (EBC) & 36.9 & 32.8 \\
\hline FAN (mg/L) & 318.59 & 181.98 \\
\hline Polyphenols (mg/L) & 226 & 181 \\
\hline Attenuation limit (\%) & 69.5 & 71.5 \\
\hline Bitterness (BU) & 34 & 36 \\
\hline \multicolumn{3}{|l|}{ Minerals (mg/L) } \\
\hline Calcium & 100 & 67 \\
\hline Magnesium & 182 & 120 \\
\hline Zinc & 0.18 & 0.12 \\
\hline Manganese & 0.32 & 0.21 \\
\hline \multicolumn{3}{|l|}{ Fermentable sugars (\%) } \\
\hline Fructose & \multicolumn{2}{|c|}{2.6} \\
\hline Glucose & \multicolumn{2}{|c|}{13.0} \\
\hline Maltose & \multicolumn{2}{|c|}{67.4} \\
\hline Maltotriose & \multicolumn{2}{|c|}{17.0} \\
\hline
\end{tabular}

the temperature was raised to the fermentation temperature. Wort fermentability was determined according Analytica-EBC ${ }^{1}$.

\section{Fermentation analysis}

Yeast cell counts were performed by microscopy cell counting using an Improved Neubauer counting camera. Viability was measured utilizing the methylene blue staining technique ${ }^{17,19}$. Samples were filtered with a $0.45 \mu \mathrm{m}$ pore size filter in the presence of kieselguhr (diatomaceous earth), to obtain clarified samples. Wort and beer gravity $\left({ }^{\circ} \mathrm{P}\right)$, fermentability (\% real degree of fermentation) and ethanol were measured using an Alcolyzer Plus, Beer Analyzing System (Anton Paar, Austria).

Selected aroma compounds for characterizing the beer profile were analyzed. Alcohols (ethanol, n-propanol, isobutanol and isoamyl alcohol), esters (ethyl acetate and isoamyl acetate), aldehyde (acetaldehyde) and diacetyl were determined by gas chromatography (Varian Star 3400) according to the European Brewery Convention recommended methods ${ }^{1}$.

\section{Residual fermenting sugars}

Wort sugar composition and beer residual sugar concentrations were determined by high-performance liquid chromatography (HPLC) using a Jasco device equipped with a refractive index detector. A Prevail Carbohydrate ES column $(5 \mu \mathrm{m}, 250 \mathrm{~mm} \times 4.6 \mathrm{~mm})$ from Alltech Associates Inc. (Deerfield, Illinois) was used. The liquid phase eluent was acetonitrile (HPLC grade, from Sigma) diluted in Milli-Q pure water $(70: 30 \mathrm{v} / \mathrm{v})^{36}$. Elution was con-


Star Chromatography Workstation software (Varian) was used to record and integrate the refractive index responses.

\section{Full factorial methodology}

A full factorial design established with commercially available software (JMP 5.01, SAS software) was used to evaluate the influence of the variables: initial dissolved oxygen $(O)$, wort extract $(W)$, fermentation temperature $(T)$ and yeast pitching rate $(Y)$ on fermentation parameters such as the fermentation time $\left(t_{\mathrm{f}}\right)$, final ethanol concentration $(E t)$, final apparent extract $\left(E_{\mathrm{a}}\right)$, real degree of fermentation $(R D F)$ and residual fermenting sugar concen-

Table II. Dimensionless process factors and respective upper and lower levels.

\begin{tabular}{lccc}
\hline & $\begin{array}{c}\text { Standardized } \\
\text { Variables formula }\end{array}$ & \multicolumn{2}{c}{ Level } \\
\cline { 4 - 5 }$O / \mathrm{ppm}$ & $x_{1}=\frac{(O-17)}{7}$ & $10 \pm 2$ & $\mathbf{- 1}$ \\
\hline$/{ }^{\circ} \mathrm{C}$ & $x_{2}=\frac{(T-15)}{3}$ & $12.0 \pm 0.2$ & $18.0 \pm 0.3$ \\
$W /{ }^{\circ} \mathrm{P}$ & $x_{3}=\frac{(W-18.5)}{3.5}$ & $15.2 \pm 0.2$ & $22.1 \pm 0.4$ \\
$Y / 10^{6} \mathrm{cell} / \mathrm{mL}$ & $x_{4}=\frac{(Y-18.5)}{3.5}$ & $15 \pm 1$ & $22 \pm 2$ \\
\hline
\end{tabular}


tration $(R F S)$. The effect was based on the estimate parameters of a linear model using the method of least squares. For generating design matrices, dimensionless process factors $\left(X_{\mathrm{i}}\right)$ were used (Table II).

Dissolved oxygen levels were chosen based on the saturation levels using sterilized air (aeration) or pure molecular oxygen (oxygenation). A wort concentration upper limit was established at $22^{\circ} \mathrm{P}$, once preliminary experiments had shown that the yeast strain could tolerate $22^{\circ} \mathrm{P}$ without performance loss (data not shown). The lower temperature limit was established at $12^{\circ} \mathrm{C}$ and the upper limit was the temperature that would allow a similar $t_{\mathrm{f}}$ as the control fermentations. Yeast pitching rate values were selected according to the proportion $10^{6}$ cell $/ \mathrm{mL}$ per each ${ }^{\circ} \mathrm{P}$.

First order polynomial equations were fitted for all process responses using experimental results:

$$
\begin{aligned}
& Y=b_{0}+b_{1} x_{1}+b_{2} x_{2}+b_{3} x_{3}+b_{4} x_{4}+b_{12} x_{1} x_{2}+ \\
& b_{13} x_{1} x_{3}+b_{14} x_{1} x_{4}+b_{23} x_{2} x_{3}+b_{24} x_{2} x_{4}+x_{34} x_{3} x_{4}
\end{aligned}
$$

Where $Y$ is the process response; $X i$ corresponds to the dimensionless process factors; $b_{0}$ is the interception coefficient; and $b_{\mathrm{i}}$ and $b_{\mathrm{ij}}$ the coefficients related to the single


Fig. 1. Apparent extract reduction in fermentations of A, oxygenated $\left(22 \mathrm{ppm}\right.$ of $\left.\mathrm{O}_{2}\right)$ wort and $\mathbf{B}$, aerated wort (10 ppm of $\mathrm{O}_{2}$ ). factors and first order interactions, respectively. Statistical analysis were performed and a $p$-value smaller than 0.05 indicated that independent variables had a significant effect on the response with a confidence level of more than $95 \%$. If the $p$-value was higher than 0.15 , the correspondent parameters had no influence on the response parameter. Between both values, it was considered that variables had a marginal effect on the response ${ }^{31}$. These criteria were followed to select the higher contributing factors and only parameters with significant $p$-values were selected into the final equations.

\section{RESULTS AND DISCUSSION}

The progress of all fermentations, performed according to extract consumption, is given in Fig. 1. The fermentations were considered complete according to a criteria widely used in lager brewery processes - apparent extract reduction in $24 \mathrm{~h}$ not higher than $0.1^{\circ} \mathrm{P}$. High gravity fermentations imply an extra downstream process, the dilution step with oxygen free water to adjust the beer concentration. Normally this step is done immediately before filling, when the beer is perfectly aged and processed by all downstream treatments. However, in this study, only the primary fermentation was considered and the green beer samples were diluted to an original extract of $11.5^{\circ} \mathrm{P}$. The yeast that settled on the bottom of the tubes at the end of the fermentations was analysed for viability. All yeast samples contained more than $85 \%$ viable cells.

Table III summarizes the observed actual values for the full factorial runs and the values predicted by the models in terms of $t_{\mathrm{f}}, E t, V$, and $E_{\mathrm{a}}$ of the green beer. The following relationships were obtained when fitting the first order polynomial equations and removing the negligible parameters from the original fitting polynomial equations.

$$
\begin{gathered}
t_{\mathrm{f}}=-1.314 \mathrm{x}_{1}-2.399 \mathrm{x}_{2}+3.086 \mathrm{x}_{3}-0.724 \mathrm{x}_{2} \mathrm{x}_{3}- \\
0.074 \mathrm{x}_{1} \mathrm{x}_{2}-0.089 \mathrm{x}_{1} \mathrm{x}_{3}+10.511 \\
E t=-0.053 \mathrm{x}_{1}+0.244 \mathrm{x}_{2}-0.007 \mathrm{x}_{3}+ \\
0.032 \mathrm{x}_{2} \mathrm{x}_{3}-0.028 \mathrm{x}_{2} \mathrm{x}_{4}-0.026 \mathrm{x}_{1} \mathrm{x}_{4}- \\
0.080 \mathrm{x}_{1} \mathrm{x}_{2}-0.053 \mathrm{x}_{3} \mathrm{x}_{4}+5.062 \\
E_{\mathrm{a}}=0.044 \mathrm{x}_{1}-0.500 \mathrm{x}_{2}+0.235 \mathrm{x}_{3}- \\
0.113 \mathrm{x}_{4}+0.181 \mathrm{x}_{1} \mathrm{x}_{2}+0.033 \mathrm{x}_{1} \mathrm{x}_{4}+ \\
0.052 \mathrm{x}_{2} \mathrm{x}_{4}-0.053 \mathrm{x}_{3} \mathrm{x}_{4}+2.460 \\
R D F=-1.600 \mathrm{x}_{1}+1.909 \mathrm{x}_{2}- \\
0.874 \mathrm{x}_{3}+0.590 \mathrm{x}_{4}+67.441
\end{gathered}
$$

The representation of the predicted response values against the experimental results indicated a good fit as all points were located close to the diagonal line (predicted values were equal to experimental values). The determination coefficients $\mathrm{R}^{2}$ of all equations (see Table IV) were all higher than 0.95 . This indicated that the equations explained more than $95 \%$ of the experimental variance. The models were analysed and compared according to the $F$ test. The larger the $F$ value the more useful the model. The lack of fit $(L O F)$ tests whether anything left out of the model was significant. The $L O F$ revealed a significant test result for the response $E_{\mathrm{a}}$, meaning that there was some significant effect that had been left out of the model and the null hypothesis could not be rejected. In these cases, 
Table III. Actual and predicted values for the full factorial run conditions and yeast viability.

\begin{tabular}{|c|c|c|c|c|c|c|c|c|c|c|c|c|c|}
\hline \multirow[b]{2}{*}{ Run \# } & \multicolumn{4}{|c|}{ Coded values } & \multicolumn{2}{|c|}{$t_{f}(\mathrm{~d})$} & \multicolumn{2}{|c|}{$E t(\%)$} & \multicolumn{2}{|c|}{$E_{a}(\%)$} & \multicolumn{2}{|c|}{$R D F(\%)$} & \multirow{2}{*}{$\begin{array}{c}\text { Viability } \\
(\%)\end{array}$} \\
\hline & $\mathbf{X}_{1}$ & $\mathbf{X}_{2}$ & $\mathbf{X}_{\mathbf{3}}$ & $\mathbf{X}_{4}$ & Act. & Pred. & Act. & Pred. & Act. & Pred. & Act. & Pred. & \\
\hline 1 & -1 & -1 & -1 & -1 & 10.3 & 10.2 & $4.8 \pm 0.2$ & 4.75 & $2.89 \pm 0.01$ & 2.98 & $67.5 \pm 0.1$ & 67.4 & 92 \\
\hline 2 & -1 & -1 & -1 & +1 & 10.3 & 10.3 & $4.90 \pm 0.02$ & 4.91 & $2.72 \pm 0.09$ & 2.68 & $68.2 \pm 0.1$ & 68.4 & 84 \\
\hline 3 & -1 & -1 & +1 & -1 & 18 & 18 & $4.64 \pm 0.08$ & 4.65 & $3.7 \pm 0.1$ & 3.61 & $66.2 \pm 0.2$ & 65.7 & 89 \\
\hline 4 & -1 & -1 & +1 & +1 & 18 & 18 & $4.83 \pm 0.08$ & 4.84 & $3.1 \pm 0.1$ & 3.11 & $67.2 \pm 0.1$ & 67.5 & 92 \\
\hline 5 & -1 & +1 & -1 & -1 & 7 & 7 & $5.39 \pm 0.03$ & 5.40 & $1.54 \pm 0.06$ & 1.54 & $71.4 \pm 0.3$ & 71.4 & 84 \\
\hline 6 & -1 & +1 & -1 & +1 & 7 & 7 & $5.42 \pm 0.01$ & 5.44 & $1.49 \pm 0.01$ & 1.46 & $72.1 \pm 0.1$ & 71.9 & 88 \\
\hline 7 & -1 & +1 & +1 & -1 & 12 & 12 & $5.40 \pm 0.06$ & 5.42 & $2.10 \pm 0.06$ & 2.12 & $68.8 \pm 0.1$ & 69.3 & 92 \\
\hline 8 & -1 & +1 & +1 & +1 & 12 & 12 & $5.54 \pm 0.01$ & 5.50 & $1.80 \pm 0.01$ & 1.83 & $71.0 \pm 0.1$ & 70.7 & 95 \\
\hline 9 & +1 & -1 & -1 & -1 & 7.9 & 7.9 & $4.82 \pm 0.01$ & 4.85 & $2.70 \pm 0.06$ & 2.67 & $64.2 \pm 0.1$ & 64.3 & 84 \\
\hline 10 & +1 & -1 & -1 & +1 & 7.9 & 7.9 & $4.91 \pm 0.03$ & 4.91 & $2.51 \pm 0.01$ & 2.51 & $65.5 \pm 0.4$ & 65.2 & 84 \\
\hline 11 & +1 & -1 & +1 & -1 & 15.4 & 15.5 & $4.8 \pm 0.2$ & 4.76 & $3.2 \pm 0.2$ & 3.24 & $61.5 \pm 0.2$ & 61.9 & 86 \\
\hline 12 & +1 & -1 & +1 & +1 & 15.4 & 15.3 & $4.87 \pm 0.01$ & 4.86 & $2.9 \pm 0.1$ & 2.87 & $64.0 \pm 0.9$ & 63.8 & 85 \\
\hline 13 & +1 & +1 & -1 & -1 & 4.5 & 4.5 & $5.17 \pm 0.04$ & 5.17 & $2.0 \pm 0.1$ & 1.95 & $68.8 \pm 0.6$ & 68.7 & 90 \\
\hline 14 & +1 & +1 & -1 & +1 & 4.5 & 4.4 & $5.14 \pm 0.08$ & 5.12 & $1.9 \pm 0.1$ & 2.00 & $69.0 \pm 0.6$ & 69.2 & 86 \\
\hline 15 & +1 & +1 & +1 & -1 & 9.3 & 9.2 & $5.2 \pm 0.2$ & 5.21 & $2.4 \pm 0.1$ & 2.47 & $66.5 \pm 0.2$ & 66.0 & 93 \\
\hline 16 & +1 & +1 & +1 & +1 & 8.6 & 8.8 & $5.14 \pm 0.01$ & 5.19 & $2.4 \pm 0.2$ & 2.31 & $67.2 \pm 0.8$ & 67.5 & 83 \\
\hline
\end{tabular}

Table IV. Summary of fit model analysis.

\begin{tabular}{lccc}
\hline Response & $\mathbf{R}^{\mathbf{2}}$ & Variance (F ratio) & Lack of fit (F ratio) \\
\hline Time & 0.999 & $4,132.03^{\mathrm{a}}$ & 3.73 \\
Ethanol & 0.963 & $74.7091^{\mathrm{a}}$ & 0.7065 \\
Final app. extract & 0.987 & $215.44^{\mathrm{a}}$ & $3.2536^{\mathrm{b}}$ \\
$R D F$ & 0.956 & $148.87^{\mathrm{a}}$ & 2.1872
\end{tabular}

${ }^{\mathrm{a}} \mathrm{p}<0.001$.

${ }^{\mathrm{b}} \mathrm{p}<0.05$.

higher order terms were needed and the models related to $E_{\mathrm{a}}$ and $V$ could not be followed.

\section{Residual fermenting sugars (RSF)}

The sweetness of a beer is due to residual sugars that have not been fermented into alcohol, and other compounds that affect the global perception of sweetness. However, in lager beers, sugars do not generally contribute to sweetness due their utilization by the yeast during the fermentation. The results can be explained by the fact that all fermentations were stopped when extract variation was $0.1^{\circ} \mathrm{P} / 24 \mathrm{~h}$, reaching identical $R F S$ concentration. Analyses of the composition of sugars in the green beer samples indicated that all monosaccharides reached a negligible residual concentration, $0.79 \pm 0.05$ and $0.031 \pm$ $0.008 \mathrm{~g} / \mathrm{L}$ for fructose and glucose respectively. The residual fructose corresponded to $16 \%$ and $25 \%$ of all of the fructose present in the $22^{\circ} \mathrm{P}$ and $15^{\circ} \mathrm{P}$ wort, respectively. In the case of glucose, the remaining concentration was only 0.1 and $0.2 \%$ of the glucose present in both the $22^{\circ} \mathrm{P}$ and $15^{\circ} \mathrm{P}$ worts, respectively. There was a significant influence between the wort concentration and the fructose residue ( $p$-value $<0.0001)$. The variation of the average concentration of fructose between the $15^{\circ} \mathrm{P}$ and $22^{\circ} \mathrm{P}$ wort was $0.18 \mathrm{~g} / \mathrm{L}$. As expected, sucrose was not identifiable in the green beer samples. This disaccharide composed of Dglucose and D-fructose, linked by an $\alpha-1,4$ glycosidic bond, is rapidly hydrolysed into glucose and fructose in the initial stages of fermentation by the action of the periplasmic enzyme invertase. This occurs prior to the sugars being transported across the cell membrane ${ }^{8}$. Maltose was the sugar present in the green beer at the highest concentration, $5.8 \pm 0.2 \mathrm{~g} / \mathrm{L}(4.5$ and $7.3 \%$ of the initial maltose present in the $22^{\circ} \mathrm{P}$ and $15^{\circ} \mathrm{P}$ wort, respectively).
Maltose concentration was significantly dependent on the fermentation temperature ( $p$-value of 0.0013 ) and wort extract ( $p$-value of 0.0384). As well as in the case of monosaccharides, the variation of residual maltose between all fermentations was small, with a confidence interval of $0.2 \mathrm{~g} / \mathrm{L}$ on the average of all trials. Regarding fermentation temperature, the maltose residue concentration decreased $0.4 \mathrm{~g} / \mathrm{L}$ when the temperature was changed from $12^{\circ} \mathrm{C}$ to $18^{\circ} \mathrm{C}$. In the case of maltotriose, $11.5 \%$ and $17.3 \%$ of the initial content were determined in green beer samples for $22^{\circ} \mathrm{P}$ and $15^{\circ} \mathrm{P}$ wort, respectively. These percentages correspond to a maltotriose average concentration of $3.46 \pm 0.09 \mathrm{~g} / \mathrm{L}$. A significant influence between temperature and maltotriose residual concentration was found $(p<0.0001)$. By increasing the fermentation temperature, the maltotriose residue decreased from an average value of $3.8 \pm 0.4 \mathrm{~g} / \mathrm{L}$ to $3.3 \pm 0.2$. The wort original extract also slightly altered the residual maltotriose from $3.4 \pm 0.2 \mathrm{~g} / \mathrm{L}\left(15^{\circ} \mathrm{P}\right)$ to $3.7 \pm 0.2 \mathrm{~g} / \mathrm{L}\left(22^{\circ} \mathrm{P}\right)$. Although the variations presented are statistically significant, the difference was small and did not produce any effect on the final product. The sum of RFS, also revealed a dependence on fermentation temperature ( $p$-value $<0.0001)$ and wort concentration ( $p$-value $<0.0001)$. When VHG wort was fermented, $10.6 \pm 0.4 \mathrm{~g} / \mathrm{L}$ of $R F S$ was left in the green beer, while with the standard $15^{\circ} \mathrm{P}$ wort, $9.6 \pm 0.4 \mathrm{~g} / \mathrm{L}$ of $R F S$ was found. Grouping the results according to fermentation temperature, a $1.3 \mathrm{~g} / \mathrm{L}$ reduction occurred when the temperature was raised from $12^{\circ} \mathrm{C}$ to $18^{\circ} \mathrm{C}$. The amounts of $R F S$ in the beer after primary fermentation followed the sugar consumption priority presented in the literature: sucrose, glucose, fructose, maltose and maltotriose ${ }^{15,52}$. The differences observed between all samples were small, and the effect on sweetness perception was not considered.

\section{Fermentation time}

Higher wort concentrations imply more sugars available to be fermented and consequently longer fermentation times. Using multiple regression analysis, $t_{\mathrm{f}}$ was described as a linear combination of oxygenation, temperature, wort concentration and pitching rate (eq. 2). According to $p$-values, all variables had a significant correlation 
Table V. Standardized estimated coefficients (weight), beta weights, and $\mathrm{t}$-value from multiple regression analyses of the fermentation time factor.

\begin{tabular}{lccc}
\hline Term & Weight & Std beta & \multicolumn{1}{c}{ t } \\
\hline $\mathrm{X}_{3}$ & 3.086 & 0.736 & $-116.02^{\mathrm{a}}$ \\
$\mathrm{X}_{2}$ & -2.399 & -0.572 & $-90.18^{\mathrm{a}}$ \\
$\mathrm{X}_{1}$ & -1.314 & -0.313 & $-49.39^{\mathrm{a}}$ \\
$\mathrm{X}_{2} * \mathrm{X}_{3}$ & -0.724 & -0.173 & $-27.21^{\mathrm{a}}$ \\
$\mathrm{X}_{1} * \mathrm{X}_{3}$ & -0.089 & -0.021 & $-3.34^{\mathrm{b}}$ \\
$\mathrm{X}_{1} * \mathrm{X}_{2}$ & -0.074 & -0.018 & $-2.77^{\mathrm{b}}$ \\
\hline
\end{tabular}

${ }^{\mathrm{a}} \mathrm{p}<0.001$.

${ }^{\mathrm{b}} \mathrm{p}<0.05$.

Table VI. Standardized estimated coefficients (weight), beta weights, and t-value from multiple regression analyses of the ethanol content factor.

\begin{tabular}{lrrc}
\hline Term & Weight & Std beta & t \\
\hline $\mathrm{X}_{3}$ & -0.007 & -0.026 & -0.67 \\
$\mathrm{X}_{2}$ & 0.244 & 0.889 & $22.15^{\mathrm{a}}$ \\
$\mathrm{X}_{1}$ & -0.053 & -0.193 & $-4.81^{\mathrm{a}}$ \\
$\mathrm{X}_{4}$ & 0.035 & 0.126 & $3.14^{\mathrm{b}}$ \\
$\mathrm{X}_{2} * \mathrm{X}_{3}$ & 0.032 & 0.155 & $2.88^{\mathrm{b}}$ \\
$\mathrm{X}_{2} * \mathrm{X}_{4}$ & -0.028 & -0.101 & $-2.53^{\mathrm{b}}$ \\
$\mathrm{X}_{1} * \mathrm{X}_{4}$ & -0.026 & -0.094 & $-2.37^{\mathrm{b}}$ \\
$\mathrm{X}_{1} * \mathrm{X}_{2}$ & -0.080 & -0.293 & $-7.30^{\mathrm{a}}$ \\
\hline
\end{tabular}

${ }^{\mathrm{a}} \mathrm{p}<0.001$.

${ }^{\mathrm{b}} \mathrm{p}<0.05$.

with $t_{\mathrm{f}}$ except $X_{4}$ (normalized variable related with the yeast pitching rate), with a marginal effect on that response $(p$-value $=0.058)($ see Table V). The equation containing the significant variables accounted for $99 \%$ of observed variance in $t_{\mathrm{f}}(\mathrm{F}=4132.03, p<0.0001)$. The range of the yeast pitching rate used in these experiments was not wide enough to alter the $t_{\mathrm{f}}$, as has been reported by other authors ${ }^{35}$. The proportion of $10^{6}$ cells $/ \mathrm{mL} /{ }^{\circ} \mathrm{P}$ was kept the same during the experiments, but for faster VHG wort fermentations, yeast pitching rate adjustments are required and higher values must be considered. Higher yeast pitching concentrations normally induce repression in the production of unsaturated fatty acids at the initial phase of the fermentation ${ }^{55}$. The most influential factors on $t_{\mathrm{f}}$ were wort extract, temperature and oxygenation level (Table V). The marginal effect of the yeast pitching rate on the processing time indicated that the values used could not reduce the long fermentation times of the VHG worts. The fermentation of a $14^{\circ} \mathrm{P}$ aerated wort, at $12^{\circ} \mathrm{C}$ using $14 \times 10^{6} \mathrm{cell} / \mathrm{mL}$, lasted 10 days and was considered the fermentation control. Without any change to the other variables except for increasing the wort concentration to $22^{\circ} \mathrm{P}$, the fermentations were completed in 18 days (Fig. 1). Some authors support an increase in the fermentation temperature to perform high gravity fermentations in a shorter period of time. By increasing the temperature from $12^{\circ} \mathrm{C}$ to $18^{\circ} \mathrm{C}$, the 18 days of $\mathrm{VHG}$ fermentations can be shortened to 12 days. The amount of dissolved oxygen has also been reported as an alternative to accelerate brewing fermentations ${ }^{34}$. The use of pure molecular oxygen to provide the required oxygen to the $15^{\circ} \mathrm{P}$ wort (instead of air saturation) can reduce the $t_{\mathrm{f}}$ from 10.3 to 8.6 days, corresponding to a $16.5 \%$ time reduction. At VHG conditions and at $12^{\circ} \mathrm{C}$ fermentation temperature, the $t_{\mathrm{f}}$ was reduced by $14.4 \%$. At $18^{\circ} \mathrm{C}$, the time saving percentage was $28.3 \%$.
Table VII. Standardized estimated coefficients (weight), beta weights, and t-value from multiple regression analyses of apparent extract factor.

\begin{tabular}{lccr}
\hline Term & Weight & Std beta & \multicolumn{1}{c}{ t } \\
\hline $\mathrm{X}_{3}$ & 0.236 & 0.390 & $16.31^{\mathrm{a}}$ \\
$\mathrm{X}_{2}$ & -0.500 & -0.828 & $-34.61^{\mathrm{a}}$ \\
$\mathrm{X}_{1}$ & 0.044 & 0.0730 & $3.05^{\mathrm{b}}$ \\
$\mathrm{X}_{4}$ & -0.114 & -0.188 & $-7.86^{\mathrm{a}}$ \\
$\mathrm{X}_{3} * \mathrm{X}_{4}$ & -0.053 & -0.087 & $-3.64^{\mathrm{b}}$ \\
$\mathrm{X}_{2} * \mathrm{X}_{4}$ & 0.052 & 0.086 & $3.61^{\mathrm{b}}$ \\
$\mathrm{X}_{1} \mathrm{X}_{2}$ & 0.181 & 0.300 & $12.53^{\mathrm{a}}$
\end{tabular}

${ }^{\mathrm{a}} \mathrm{p}<0.001$.

${ }^{\mathrm{b}} \mathrm{p}<0.05$.

Table VIII. Standardized estimated coefficients (weight), beta weights, and t-value from multiple regression analyses of real degree of fermentation factor.

\begin{tabular}{lrrr}
\hline Term & Weight & Std beta & t \\
\hline $\mathrm{X}_{1}$ & -1.601 & -0.579 & $608.41^{\mathrm{a}}$ \\
$\mathrm{X}_{2}$ & 1.909 & 0.690 & $-14.44^{\mathrm{a}}$ \\
$\mathrm{X}_{3}$ & -0.874 & -0.316 & $17.22^{\mathrm{a}}$ \\
$\mathrm{X}_{4}$ & 0.590 & 0.213 & $-7.88^{\mathrm{a}}$ \\
\hline${ }^{\mathrm{a}} \mathrm{p}<0.001$. & &
\end{tabular}

\section{Final ethanol concentration}

The effect of the evaluated fermentation parameters on the ethanol content of diluted beer (eq. 3), accounted for $96 \%$ of the observed variance $(\mathrm{F}=74.71, \mathrm{p}<0.0001)$. All variables had an influence on the final ethanol concentration, except $X_{3}$, which is only influential when combined with other variables (see Table VI). This indicates that increasing the gravity of the wort does not result in a direct change in the ethanol content of the diluted beer. However, a higher influence was observed when the temperature was increased from $12^{\circ} \mathrm{C}$ to $18^{\circ} \mathrm{C}$ (estimated coefficient of 0.244). It should be considered that in rapid fermentations induced by higher temperatures, the intracellular ethanol accumulation could perhaps be higher than what the yeast is able to diffuse, compromising the consistency of yeast performance ${ }^{34}$.

\section{Final apparent extract}

The equation containing the significant variables for the final apparent extract (eq. 4) accounted for $98.7 \%$ of the observed variance $(F=215.44, \mathrm{p}<0.0001)$. All variables had a significant effect on the final apparent extract and temperature had the strongest effect, with a negative estimated coefficient of -0.500 , and the wort extract, as expected, also influenced the final apparent extract ${ }^{9}$ (see Table VII). The differences in the apparent residual extract caused by increasing wort extract can be solved by using a higher fermentation temperature or a higher yeast pitching rate, although the maximal experimental pitching rate used in this work was not enough to compensate for this.

\section{Real degree of fermentation (RDF)}

The real degree of fermentation was also related with the studied variables (eq. 5). The equation containing the significant variables accounted for $95.7 \%$ of observed variance $R D F(F=148.87, \mathrm{p}<0.0001)$. The real degree of fermentation is the percentage of the total solids of the original wort utilized during processing. Although all variables significantly influence the $R D F$, no interactions were observed between them (Table VIII). The tempera- 
Table IX. Experimental values for n-propanol $(n P)$, isobutanol ( $i B)$, ethyl acetate $(e A c)$, amyl acetate $(a A c)$, total esters $(t E)$, acetaldehyde $(a A l d)$, amyl alcohols $(a A l)$, and total alcohols $(t A l)$ in the diluted green beer samples.

\begin{tabular}{|c|c|c|c|c|c|c|c|c|c|c|c|c|}
\hline \multirow[b]{2}{*}{ Run \# } & \multicolumn{4}{|c|}{ Coded values } & \multirow[b]{2}{*}{$n P(\mathrm{mg} / \mathrm{L})$} & \multirow[b]{2}{*}{$i B(\mathrm{mg} / \mathrm{L})$} & \multirow[b]{2}{*}{$e A c(\mathrm{mg} / \mathrm{L})$} & \multirow[b]{2}{*}{$a A c(\mathrm{mg} / \mathrm{L})$} & \multirow[b]{2}{*}{$t E(\mathrm{mg} / \mathrm{L})$} & \multirow[b]{2}{*}{ aAld. $(\mathrm{mg} / \mathrm{L})$} & \multirow[b]{2}{*}{$a A l(\mathrm{mg} / \mathrm{L})$} & \multirow[b]{2}{*}{$t A l(\mathrm{mg} / \mathrm{L})$} \\
\hline & $\mathrm{X}_{1}$ & $\mathbf{X}_{2}$ & $\mathbf{X}_{3}$ & $\mathbf{X}_{4}$ & & & & & & & & \\
\hline 1 & -1 & -1 & -1 & -1 & $18 \pm 1$ & $15 \pm 1$ & $14 \pm 2$ & $1.1 \pm 0.3$ & $16 \pm 3$ & $9.2 \pm 0.1$ & $81 \pm 13$ & $114 \pm 12$ \\
\hline 2 & -1 & -1 & -1 & +1 & $21 \pm 4$ & $15 \pm 4$ & $21 \pm 1$ & $1.4 \pm 0.1$ & $22 \pm 1$ & $9.2 \pm 0.2$ & $69 \pm 9$ & $105 \pm 17$ \\
\hline 3 & -1 & -1 & +1 & -1 & $15 \pm 1$ & $11 \pm 2$ & $25 \pm 10$ & $1.4 \pm 0.1$ & $26 \pm 11$ & $6.9 \pm 0.9$ & $63 \pm 8$ & $89 \pm 12$ \\
\hline 4 & -1 & -1 & +1 & +1 & $14 \pm 4$ & $12 \pm 1$ & $32 \pm 1$ & $1.3 \pm 0.1$ & $33 \pm 2$ & $6.0 \pm 0.8$ & $66 \pm 1$ & $92 \pm 2$ \\
\hline 5 & -1 & +1 & -1 & -1 & $27 \pm 4$ & $24 \pm 1$ & $27 \pm 1$ & $2.5 \pm 0.1$ & $29 \pm 1$ & $3 \pm 1$ & $103 \pm 1$ & $155 \pm 4$ \\
\hline 6 & -1 & +1 & -1 & +1 & $29 \pm 3$ & $24 \pm 1$ & $21.0 \pm 0.2$ & $2.3 \pm 0.5$ & $23.3 \pm 0.5$ & $2.5 \pm 0.1$ & $99 \pm 1$ & $153 \pm 1$ \\
\hline 7 & -1 & +1 & +1 & -1 & $24 \pm 1$ & $17 \pm 1$ & $37 \pm 4$ & $2.1 \pm 0.4$ & $39 \pm 5$ & $7 \pm 2$ & $97 \pm 1$ & $138 \pm 1$ \\
\hline 8 & -1 & +1 & +1 & +1 & $29 \pm 2$ & $17 \pm 4$ & $39 \pm 1$ & $1.9 \pm 0.2$ & $41 \pm 1$ & $3.8 \pm 0.9$ & $89 \pm 6$ & $136 \pm 3$ \\
\hline 9 & +1 & -1 & -1 & -1 & $16 \pm 1$ & $14 \pm 1$ & $18 \pm 4$ & $1.3 \pm 0.6$ & $19 \pm 5$ & $8.1 \pm 0.3$ & $68 \pm 2$ & $99 \pm 4$ \\
\hline 10 & +1 & -1 & -1 & +1 & $16 \pm 3$ & $13 \pm 3$ & $23 \pm 1$ & $1.7 \pm 0.1$ & $25 \pm 1$ & $8.9 \pm 0.2$ & $64 \pm 10$ & $93 \pm 16$ \\
\hline 11 & +1 & -1 & +1 & -1 & $12 \pm 2$ & $9 \pm 1$ & $32 \pm 1$ & $1.7 \pm 0.2$ & $34.2 \pm 0.1$ & $5.6 \pm 0.2$ & $60 \pm 9$ & $81 \pm 12$ \\
\hline 12 & +1 & -1 & +1 & +1 & $13 \pm 1$ & $10 \pm 1$ & $35.9 \pm 0.2$ & $1.8 \pm 0.1$ & $37.6 \pm 0.3$ & $5.0 \pm 0.1$ & $63 \pm 1$ & $91 \pm 8$ \\
\hline 13 & +1 & +1 & -1 & -1 & $23 \pm 4$ & $22 \pm 1$ & $29.1 \pm 0.2$ & $3.3 \pm 0.4$ & $32 \pm 1$ & $1.5 \pm 0.2$ & $99 \pm 1$ & $143 \pm 5$ \\
\hline 14 & +1 & +1 & -1 & +1 & $24 \pm 4$ & $20 \pm 1$ & $25 \pm 1$ & $2.5 \pm 0.1$ & $27 \pm 1$ & $1.3 \pm 0.2$ & $86 \pm 6$ & $130 \pm 10$ \\
\hline 15 & +1 & +1 & +1 & -1 & $18 \pm 1$ & $14 \pm 1$ & $40 \pm 2$ & $2.7 \pm 0.8$ & $42 \pm 3$ & $7 \pm 2$ & $83 \pm 4$ & $114 \pm 3$ \\
\hline 16 & +1 & +1 & +1 & +1 & $18 \pm 1$ & $13 \pm 2$ & $40.8 \pm 0.1$ & $2.6 \pm 0.1$ & $44 \pm 1$ & $2.8 \pm 0.1$ & $73 \pm 1$ & $106 \pm 1$ \\
\hline
\end{tabular}

ture and yeast pitching rate had a positive influence on the degree of fermentation. Increasing the wort extract from $15^{\circ} \mathrm{P}$ to $22^{\circ} \mathrm{P}$ and with keeping all other variables at middle value (average between lower and upper experimental limits); more than $1.9 \%$ of dissolved solids in the wort were left out of processing. Wort fermentability tests were carried out resulting in a $R D F$ of $72 \pm 3$ and $69 \pm 2$ for $15^{\circ} \mathrm{P}$ and $22^{\circ} \mathrm{P}$ worts, respectively. These degrees of fermentation were reached at $18^{\circ} \mathrm{C}$ using aerated wort. The degree of fermentation decreased when using pure oxygen to provide molecular oxygen to the wort (estimated parameter of -1.601). The temperature and yeast pitching rate were the factors with a positive effect on $R D F$.

\section{Impact on beer aroma profile}

Aromatic composition of the green beer samples are presented in the Table IX in terms of n-propanol $(n P)$, isobutanol $(i B)$, amyl alcohols $(a A l)$, total alcohols $(t A l)$, ethyl acetate $(e A c)$, amyl acetate $(a A c)$, total esters $(t E)$ and acetaldehyde $(a A l d)$ content. Typical concentration of higher alcohols in beers is of the order of $100-200 \mathrm{mg} / \mathrm{L}^{28}$ and generally, any parameter that extends the yeast growth produces a concomitant increase in higher alcohol concentrations. Dilution of the green beer to $11.5^{\circ} \mathrm{P}$ resulted in higher alcohol concentration, between 77 and $155 \mathrm{mg} / \mathrm{L}$. According to the results, only the pitching rate did not significantly affect the concentration of total alcohols, when the experimental conditions ranged between 14 and 22 million cells $/ \mathrm{mL}$. Concerning the fermentation temperature, an increase in the production of higher alcohols was observed when $18^{\circ} \mathrm{C}$ was used instead of $12^{\circ} \mathrm{C}$. This variation was expected based on the literature ${ }^{25}$, confirming that temperature was the most influential variable in higher alcohol production. When sterilized air was used to supply oxygen to the wort, the green beer obtained at $18^{\circ} \mathrm{C}$ had $43 \%\left(15^{\circ} \mathrm{P}\right)$ and $44 \%\left(22^{\circ} \mathrm{P}\right)$ higher alcohols than the beer fermented at $12^{\circ} \mathrm{C}$. Similar percentages were observed for the fermentation with oxygenated wort. The higher alcohol production increased when the wort concentration was raised from $15^{\circ} \mathrm{P}$ to $22^{\circ} \mathrm{P}$. However, when green beer samples were diluted to $11.5^{\circ} \mathrm{P}$, a reduction was observed in the higher alcohol content when the wort concentration was raised.
Concerning beer ester composition, lager beers have typical concentrations up to $60 \mathrm{mg} / \mathrm{L}^{24}$. The samples of green beer contained between $16 \pm 3$ and $44 \pm 1 \mathrm{mg} / \mathrm{L}$ of esters (Table IX). Wort concentration was the variable with the largest influence on the ester concentration in the green beer, followed by the temperature of the fermentation. High gravity brewing usually results in an over production of esters, resulting in a more fruity and solventlike beers ${ }^{18}$. The wort concentration was the variable with the highest weight on the total ester effect (Table IX), following the reported tendency ${ }^{2,30}$. The fermentation of the $22^{\circ} \mathrm{P}$ wort increased ester formation by $57 \%$ (total average) when compared to the $15^{\circ} \mathrm{P}$ wort. Temperature had a positive effect on ester formation, again in accordance with the literature ${ }^{46}$. Ethyl acetate, an ester responsible for fruity aroma in the beer (threshold of $30 \mathrm{mg} / \mathrm{L}^{28}$ ) presented the highest variation observed for total esters. Nevertheless, the perception of amyl acetate (banana aroma) variations caused by changed fermentation parameters could occur because of its low threshold, ranging between $1.0-1.6 \mathrm{mg} / \mathrm{L}$.

Acetaldehyde, the most important aldehyde in beer, was the most affected by the fermentation temperature and wort concentration. With increasing fermentation temperature, acetaldehyde concentration in the green beer decreased, but when it was combined with $22^{\circ} \mathrm{P}$ wort, the concentration increased. Considering that the acetaldehyde threshold is about $10 \mathrm{mg} / \mathrm{L}^{28}$, it is noted that even in green beer samples, the undesirable flavour of the acetaldehyde was not perceptible.

\section{Verification of the model equations}

A set of four fermentations were carried out to verify the model equations. Fermentations V3 and V4 corresponded to the validation of the conditions used in the modelling fermentations. On the other hand, fermentations V1 and V2 were performed under intermediate conditions relative to wort conditions, and all conditions were conducted in duplicate. Predicted values were obtained by substitution of the experimental conditions on the equations (2) to (6). These were compared with the actual values, reported as the percentage of the variation between predicted and actual values (Fig. 2). 


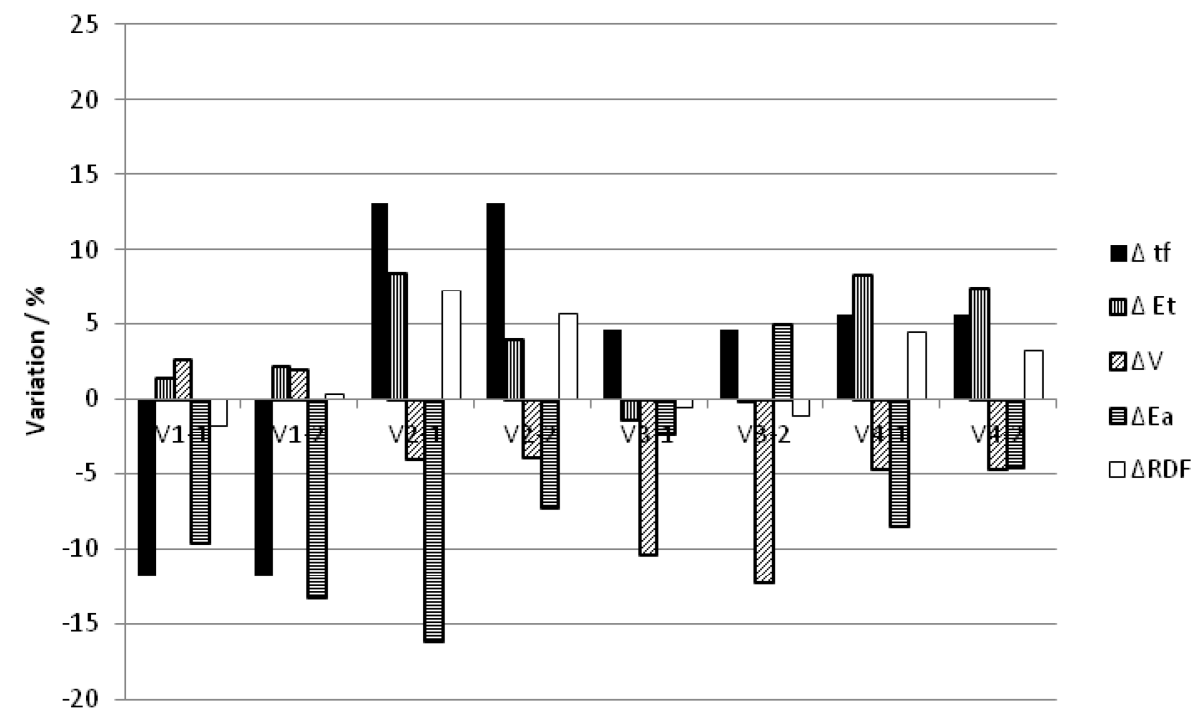

Fig. 2. Variation between predicted and actual responses for verification fermentations.

According to the duplicates, a consistent variation between predicted and actual results can be observed by comparing V-1 and V-2. This is due to the minor error between duplicates in the fermentation monitoring analysis. Analyzing the amplitude of the variation, higher deviations to the predicted values were observed with $E a$ and $t_{\mathrm{f}}$. However, lower variations were found for the conditions used for modelling.

\section{Optimization}

Since the operating variables influence the process responses response in different ways, process optimization is a complex problem. The 'desirability function' of the JMP software ${ }^{48}$ was used to find the optimal conditions for multiple responses and to solve the trade-off between them. To run the maximization of the desirability, it was considered that all the responses had the same importance with the following targets:

- Minimization of $t_{f}$

- Maximization of $E t$

- Minimization of $E a$

- Maximization of the $R D F$

The optimal operating conditions were found to be 22 ppm for dissolved oxygen in the wort $\left(\mathrm{X}_{1}\right), 18^{\circ} \mathrm{C}$ for fermentation temperature $\left(\mathrm{X}_{2}\right), 22^{\circ} \mathrm{P}$ for wort extract $\left(\mathrm{X}_{3}\right)$ and $22 \times 10^{6}$ cell $/ \mathrm{mL}$ for yeast pitching rate $\left(\mathrm{X}_{4}\right)$. A desirability of 0.73 was achieved, meaning that $73 \%$ of the goals were achieved. These conditions result in a $t_{\mathrm{f}}$ of 11.9 \pm 0.2 days and a $R D F$ of $70.7 \pm 0.7 \%$. The beer dilution increased the volume in $101 \pm 3 \%$, resulting in a beer containing $5.50 \pm 0.08 \%$ of ethanol and an apparent extract of $1.8 \pm 0.1^{\circ} \mathrm{P}$.

\section{CONCLUSIONS}

Variable interactions are complex and influence fermentation efficiency regarding process time and the extent of sugar consumption. RFS analyses indicate that the brewer's yeast strain that was used was able to ferment wort concentrations up to $22^{\circ} \mathrm{P}$ without prematurely inter- rupting sugar consumption. The variation in the concentration of each sugar for all the trials was less than $1 \mathrm{~g} / \mathrm{L}$.

By increasing the wort extract from $15^{\circ} \mathrm{P}$ to $22^{\circ} \mathrm{P}$, the brewing volumetric capacity was increased in a very attractive way. Analysis of the variance and linear regression showed that the $t_{\mathrm{f}}$ of primary fermentation was mainly influenced by the wort concentration and fermentation temperature. The obtained models demonstrated a linear variation between the responses $t_{\mathrm{f}}, E_{\mathrm{a}}$ and $R D F$ and the studied environmental variables, for the experimented range. It should be underlined that this behaviour is limited to the selected range for the studied variables.

Nevertheless, results suggest that the $t_{\mathrm{f}}$ of a $22^{\circ} \mathrm{P}$ wort fermentations can be reduced to the control $t_{\mathrm{f}}$ using temperatures not higher than $18^{\circ} \mathrm{C}$, combined with a higher level of dissolved oxygen. The utilization of pure oxygen reduces the ethanol content of the diluted beer and the $R D F$. According to the optimization criteria, which states that all responses have the same coefficient of interest in the desirability function, this work suggests the use of compressed air to ferment VHG worts, instead of oxygenation with pure oxygen gas, even if a negative effect on the $t_{\mathrm{f}}$ occurs.

The effect of the operational variables on the most important aromatic compounds was limited. Within the range of tested conditions, the concentrations of the higher alcohols did not change beyond the respective thresholds, as well as the acetaldehyde concentration. However, regarding ester variation, the concentrations obtained at the very high gravity conditions could affect the aroma profile once the concentration of ethyl acetate and amyl acetates exceeds the threshold level. This suggests that beer produced with very high gravity worts would acquire a fruity aroma when compared with beer produced from normal gravity worts.

In order to obtain a beer with $11.5^{\circ} \mathrm{P}$ of original extract, the dilution step would increase the volumetric yield of the global process. The dilution of the beer from the fermentation of a $22^{\circ} \mathrm{P}$ wort would give a gain of $91 \%$ of the real fermented volume, while the $15^{\circ} \mathrm{P}$ wort would correspond to a $30 \%$ gain. 


\section{ACKNOWLEDGEMENTS}

The authors thank Unicer - Bebidas de Portugal, S.A. for the support with physical facilities and all analysis carried out at Central Laboratory. Luis Lima thanks Unicer- Bebidas de Portugal, S.A and Fundação para a Ciência e Tecnologia for his $\mathrm{PhD}$ scholarship (SFRH/BDE/15637/2006).

\section{REFERENCES}

1. Analytica EBC, European Brewing Convention. Verlag Hans Carl Getränke-Fachverlag: Nürnberg, Germany, 1998.

2. Anderson, R. G. and Kirsop, B. H., The control of volatile ester synthesis during the fermentation of wort of high specific gravity. J. Inst. Brew., 1974, 80, 48-55.

3. Bardi, E., Koutinas, A. A. and Kanellaki, M., Room and low temperature brewing with yeast immobilized on gluten pellets. Process Biochem., 1997, 32, 691-696.

4. Barker, R. L., Irwin, A. J. and Murray, C. R., The relationship between fermentation variables and flavor volatiles by direct gas chromatographic injection of beer. Tech. Q. Master Brew. Assoc. Am., 1992, 29, 11-17.

5. Blieck, L., Toye, G., Dumortier, F., Verstrepen, K. J., Delvaux, F. R., Thevelein, J. M. and Van Dijck, P., Isolation and characterization of brewer's yeast variants with improved fermentation performance under high-gravity conditions. Appl. Environ. Microbiol., 2007, 73, 815-824.

6. Casey, G. P., Magnus, C. A., and Ingledew, W. M., High-Gravity brewing - effects of nutrition on yeast composition, fermentative ability, and alcohol production. Appl. Environ. Microbiol., 1984, 48, 639-646.

7. Casey, G. P. and Ingledew, W. M., Ethanol tolerance in yeasts. Crit. Rev. Microbiol., 1986, 13, 219-280.

8. D'Amore, T., Ethanol tolerance of yeast. Enzyme Microb. Technol., 1987, 9, 322-330.

9. D'Amore, T., Cambridge Prize Lecture-Improving yeast fermentation performance. J. Inst. Brew, 1992, 98, 375-382.

10. D'Amore, T., Panchal, C. J., Russell, I. and Stewart, G. G., Osmotic pressure effects and intracellular accumulation of ethanol in yeast during fermentation. J. Ind. Microbiol., 1988, 2, 365-372.

11. Daum, G., Lees, N. D., Bard, M. and Dickson, R., Biochemistry, cell biology and molecular biology of lipids of Saccharomyces cerevisiae. Yeast, 1998, 14, 1471-1510.

12. Defernez, M., Foxall, R., Omalley, C., Montague, G., Ring, S. and Kemsley, E., Modelling beer fermentation variability. $J$. Food. Eng., 2007, 83, 167-172.

13. Demel, R. A. and De Kruyff, B., The function of sterols in membranes. Biochim. Biophys. Acta, 1976, 457, 109-132.

14. Ding, J., Huang, X., Zhang, L., Zhao, N., Yang, D. and Zhang, K., Tolerance and stress response to ethanol in the yeast Saccharomyces cerevisiae. Appl. Microbiol. Biotechnol., 2009, 85, 253-263.

15. Ernandes, J. R., Williams, J. W., Russell, I. and Stewart, G. G., Effect of yeast adaptation to maltose utilization on sugar uptake during the fermentation of the brewer's wort. J. Inst. Brew. 1993, 99, 67-71.

16. Erten, H., Tanguler, H. and Cakiroz, H., The effect of pitching rate on fermentation and flavour compounds in high gravity brewing. J. Inst. Brew., 2007, 113, 75-79.

17. Garcia, A. I., Garcia, L. A. and Diaz, M., Prediction of ester production in industrial beer fermentation. Enzyme Microb. Technol., 1994, 16, 66-71.

18. Garcia, A. I., Garcia, L. A., and Diaz, M., Modeling of diacetyl production during beer fermentation. J. Inst. Brew., 1994, 100, 179-183.

19. Heggart, H., Margaritis, A., Stewart, R. J., Pilkington, M., Sobczak, J. and Russell, I., Measurement of brewing yeast viability and vitality: A review of methods. Tech. Q. Master Brew. Assoc. Am., 2000, 37, 409-430.

20. Huseyin, E., Tanguler, H. and Cakiroz, H., The effect of pitching rate on fermentation and flavour compounds in high gravity brewing. J. Inst. Brew., 2007, 113, 75-79.
21. Huuskonen, A., Markkula, T., Vidgren, V., Lima, L., Mulder, L., Geurts, W., Walsh, M. and Londesborough, J., Selection from industrial lager yeast strains of variants with improved fermentation performance in very-high-gravity worts. Appl. Environ. Microbiol., 2010, 76, 1563-1573.

22. Ingledew, W. M., Magnus, C. A. and Sosulski, F. W., Influence of oxygen on proline utilization during the wine fermentation. Am. J. Enol. Vitic., 1987, 38, 246-248.

23. Jakobsen, M. and Piper, J. U., Performance and osmotolerance of different strains of lager yeast in high gravity fermentations. Tech. Q. Master Brew. Assoc. Am., 1989, 26, 86-61.

24. Kunze, W., Technology Brewing and Malting, VLB: Berlin, 2004.

25. Landaud, S., Latrille, E. and Corrieu, G., Top pressure and temperature control the fusel alcohol/ester ratio through yeast growth in beer fermentation. J. Inst. Brew., 2001, 107, 107-117.

26. Liu, Z., Zhang, G., and Sun, Y., Mutagenizing brewing yeast strain for improving fermentation property of beer. J. Biosci. Bioeng., 2008, 106, 33-38.

27. Man, V., Using high pitching rate for improvement of yeast fermentation performance in high gravity brewing. Int. Food Res. J., 2009, 16, 547-554.

28. Meilgaard, M. C., Flavor chemistry of beer - Part II: Flavour and threshold of 239 aroma volatiles. Tech. Q. Master Brew. Assoc. Am., 1975, 12, 151-168.

29. Meilgaard, M. C., Flavor chemistry of beer. I. Flavor interaction between principal volatiles. Tech. Q. Master Brew. Assoc. Am., 1976, 12, 107-117.

30. Meilgaard, M. C., Effects on flavour of innovations in brewery equipment and processing: a review. J. Inst. Brew, 2001, 107, 271-286.

31. Montgomery, D. C., Design and Analysis of Experiments, 5th Edition, John Wiley \& Sons: New York, 2001.

32. Morris, G. J., Winters, L., Coulson, G. E. and Clarke, K. J., Effect of osmotic stress on the ultrastructure and viability of the yeast Saccharomyces cerevisiae. J. Gen. Microbiol., 1986, 132, 2023-2034.

33. Murray, D., Cahill, G., Walsh, P. and Donnelly, D., Effect of the concentration of propagation wort on yeast cell volume and fermentation performance. J. Am. Soc. Brew. Chem., 2000, 58, 112-121.

34. Nagodawithana, T. W. and Steinkraus, K. H., Influence of the rate of ethanol production and accumulation on the viability of Saccharomyces cerevisiae in "rapid fermentation". Appl. Environ. Microbiol., 1976, 31, 158-162.

35. Nielsen, O., Control of the yeast propagation process- how to optimize oxygen supply and minimize stress. Yeast, 2005, 42, 128-132.

36. Nobre, C., Santos, M. J., Dominguez, A., Torres, D., Rocha, O., Peres, A. M., Rocha, I., Ferreira, E. C., Teixeira, J. A. and Rodrigues, L. R., Comparison of adsorption equilibrium of fructose, glucose and sucrose on potassium gel-type and macroporous sodium ion-exchange resins. Analytica Chimica Acta, 2009, 654, 71-76.

37. O'Rourke, T., The role of oxygen in brewing. Brew. Int., 2002, March, 45-47.

38. O'Connor, E. S. C. and Ingledew, W. M., Effect of the timing of oxygenation on very high gravity brewing fermentations. J. Am. Soc. Brew. Chem., 1990, 48, 26-32.

39. O'Connor-Cox, E. S., Lodolo, E. J. and Axcell, B. C., Role of oxygen in high-gravity fermentations in the absence of unsaturated lipid biosynthesis. J. Am. Soc. Brew. Chem., 1993, 51, 97107.

40. O'Connor-Cox, E., Lodolo, E., and Axcell, B., Mitochondrial relevance to yeast fermentative performance: a review. J. Inst. Brew., 1996, 102, 19-25.

41. Odumeru, J. A., D'Amore, T., Russell, I., and Stewart, G. G., Effects of heat shock and ethanol stress on the viability of a Saccharomyces uvarum (carlsbergensis) brewing yeast strain during fermentation of high gravity wort. J. Ind. Microbiol., 1992, 10, 111-116. 
42. Peddie, H., Ester formation in brewery fermentations. J. Inst. Brew., 1990, 96, 327-331.

43. Pratt, P., Bryce, J. and Stewart, G. G., The effects of osmotic pressure and ethanol on yeast viability and morphology. J. Inst. Brew., 2003, 109, 218-228.

44. Ramirez, W., Optimal beer fermentation. J. Inst. Brew., 2007, 113, 325-333.

45. Renger, R. S., van Hateren, S. H. and Luyben, K. A. M., The formation of esters and higher alcohols during brewery fermentation; the effect of carbon dioxide pressure. J. Inst. Brew., 1992, 98, 509-513.

46. Saerens, S. M. G., Verbelen, P. J., Vanbeneden, N., Thevelein, J. M. and Delvaux, F. R., Monitoring the influence of high-gravity brewing and fermentation temperature on flavour formation by analysis of gene expression levels in brewing yeast. Appl. $\mathrm{Mi}$ crobiol. Biotechnol., 2008, 80, 1039-1051.

47. Saerens, S. M. G., Delvaux, F., Verstrepen, K. J., Van Dijck, P., Thevelein, J. M., and Delvaux, F. R., Parameters affecting ethyl ester production by Saccharomyces cerevisiae during fermentation. Appl. Environ. Microbiol., 2008, 74, 454-461.

48. Sall, J., Creighton, L. and Lehman, A., JMP Start Statistics: a Guide to Statistics and Data Analysis Using JMP. 47, SAS Institute: Carey, NC, 2005.

49. Sigler, K., Matoulkova, D., Dienstbier, M. and Gabriel, P., Net effect of wort osmotic pressure on fermentation course, yeast vitality, beer flavor, and haze. Appl. Microbiol. Biotechnol., 2009, 82, 1027-1035.

50. Stewart, G. G., Bothwick, R., Bryce, J., Cooper, D., Cunningham, S., Hart, C. and Rees, E., Recent developments in high gravity brewing. Tech. Q. Master Brew. Assoc. Am., 1997, 34, 264-270.
51. Suihko, M., Vilpola, A. and Linko, M., Pitching rate in high gravity brewing. J. Inst. Brew., 1993, 99, 341-346.

52. Thomas, K. C. and Ingledew, W. M., Production of $21 \%$ (v/v) ethanol by fermentation of very high gravity (VHG) wheat mashes. J. Ind. Microbiol., 1992, 10, 61-68.

53. Trelea, I., Predictive modelling of brewing fermentation: from knowledge-based to black-box models. Math Comput. Simulat., 2001, 56, 405-424.

54. Trelea, I., Dynamic optimisation of the aroma production in brewing fermentation. J. Process Control, 2004, 14, 1-16.

55. Verbelen, P. J., Dekoninck, T. M. L., Saerens, S. M. G., Van Mulders, S. E., Thevelein, J. M. and Delvaux, F. R., Impact of pitching rate on yeast fermentation performance and beer flavour. Appl. Microbiol. Biotechnol., 2009, 82, 155-167.

56. Verbelen, P. J., Saerens, S. M. G., Van Mulders, S. E., Delvaux, F. and Delvaux, F. R., The role of oxygen in yeast metabolism during high cell density brewery fermentations. Appl. Microbiol. Cell Physiol., 2009, 82, 1143-1156.

57. Verstrepen, K. J., Derdelinckx, G., Dufour, J. P., Winderickx, J., Thevelein, J. M., Pretorius, I. S. and Delvaux, F. R., Flavor-active esters: adding fruitiness to beer. J. Biosci. Bioeng., 2003, 96, 110-118.

58. Yokoyama, A. and Ingledew, W. M., The effect of filling procedures on multi-fill fermentations. Tech. Q. Master Brew. Assoc. Am., 1997, 34, 320-327.

(Manuscript accepted for publication September 2011) 